\title{
Feed evaluation by measurement of sites of digestion in cannulated ruminants
}

\section{By J. D. Sutton and J. D. Oldham, National Institute for Research in Dairying, Shinfield, Reading RG2 $9 A T$}

The value of feeds depends primarily on the amount and balance of nutrients absorbed from the digestive tract. Most feeding systems are based either on measurement of the over-all efficiency of utilization of feeds, as in net energy systems, or on estimation of the amounts of digestible or metabolizable nutrients produced in the digestive tract on the one hand, and the efficiency with which these nutrients are used on the other. In the United Kingdom, schemes for basing feeding systems for ruminants on the second approach have been proposed by the Agricultural Research Council for both energy (ARC, 1965) and protein (Roy, Balch, Miller, Ørskov \& Smith, 1977). Feeds must therefore be evaluated in terms of the metabolizable nutrients they contain, but because of the complex digestive system of the ruminant, these bear little relation to apparently digested nutrients as measured by collection of faeces.

To attempt to overcome the problem, a widely used technique has been measurement of the extent of digestion in different sections of the gut by the use of gastro-intestinal cannulas. For protein, it can yield reasonably accurate measures of the degradability of feed protein and microbial synthesis in the rumen and of the apparent digestibility of amino acids in the small intestine. The availability of this information has led to several schemes for basing the protein evaluation of feeds on their contribution to the supply of amino acids to the tissues.

For energy, the situation is more complex. The transformations undergone during digestion are much greater for carbohydrates than for protein and, as discussed by Sutton (1976), additional techniques, such as the use of radioactive tracers and measurement of blood flow, are required to provide estimates of nutrient uptake. The importance of such information has been stressed by Moe \& Tyrrell (1973), but the techniques are not well suited to routine feed evaluation and current proposals (ARC, 1965) use a different approach to determine the metabolizable energy content of feeds. In this review, methods of measuring digesta flow will therefore be considered mainly in relation to their application to predicting the protein value of feeds.

\section{Technique}

Cannulation. The basic requirement is to measure flow of digesta from the forestomach to the abomasum and from the terminal ileum into the large intestine. Cannulation of the omasum is very difficult and most workers rely on cannulas in 
the abomasum or in the first few centimetres of the duodenum to provide measures of flow from the forestomach. Because of surgical problems, in most published experiments with adult cattle cannulas have been placed beyond the point of entry of the bile and pancreatic ducts. Flow out of the small intestine is measured by means of cannulas in the terminal ileum.

In the intestines cannulation is achieved either with a simple $T$-shaped cannula inserted into a fistula in the gut, or by re-entrant $(\mathrm{R} / \mathrm{E})$ cannulation for which the intestine is transected and flow of digesta is exteriorized through two cannulas which are inserted into, or near to the cut ends of the intestine and joined externally. In the abomasum only simple cannulas are used.

Normality of the animals. It is essential that these surgical modifications should not cause appreciable disturbance of digestive function, yet few groups have attempted to assess the normality of their animals. Corse \& Sutton (r97I and unpublished results) found intake and digestibility of hay and concentrates in eight sheep provided with rumen and either simple or $R / E$ duodenal cannulas to be slightly higher than that measured before surgery. The effect of similar cannulation of ten dairy cows, conducted when they were 5-7 months in calf $(\mathrm{H}$. L. Buttle, J. D. Oldham \& J. D. Sutton, unpublished results), has been studied by comparing the performance of the cows for about 8 weeks after calving with that of a non-fistulated group. All the cows were offered the same ration of hay and concentrates at about $90 \%$ of ad lib. intake and all the fistulates except one ate $95 \%$ or more of the ration. Peak milk yield was the same in the three groups at about $28 \mathrm{~kg} / \mathrm{d}$, but there was a tendency for a slightly lower milk fat content in the two fistulated groups.

These results from our own Institute are reassuring but each group must assess the performance of its own animals as much depends on the skill of the surgeon and the post-operative care by the staff.

Markers. Intestinal markers are an essential feature of collections from simple cannulas and they have also been used in most collections from re-entrant cannulas (see MacRae (1974); Faichney (1975)). The flow of a marker through the tract must coincide as closely as possible with that of the digesta which can be considered to consist of two phases, one liquid and the other solid. To try to achieve this, markers are usually infused continuously into the rumen or introduced in a slow-release form. Chromic oxide impregnated on paper is the most widely used example of the latter system but it has the disadvantage that the chromic oxide does not associate with any particular fraction of the digesta. A more satisfactory system is one involving the continuous infusion of a watersoluble marker for the liquid phase and a marker that can attach to the particulate matter for the solid phase. The combination of ${ }^{51} \mathrm{Cr}$-EDTA and the phenanthroline complex of ${ }^{103} \mathrm{Ru}$ has yielded satisfactory results, but radioactive markers cannot be used in all situations and the use of non-radioactive forms in milking cows is being studied at this Institute.

Use of $R / E$ cannulas. Usually all digesta passing through the cannula are collected, sampled and returned, this being done either manually or with varying 
degrees of automation (Corse, 1974). Because all the digesta are collected and sampled, this technique offers a very accurate means of measuring flow, but incomplete recovery of markers in $24 \mathrm{~h}$ collections led to the suggestion that the rate of flow may often be at least temporarily reduced by the collection procedure itself.

To study this problem, digesta flow has been measured for $5 \mathrm{~d}$ in dry cows (Sutton et al. 1976) and 6 or $7 \mathrm{~d}$ in sheep (D. J. Thomson \& D. E. Beever, unpublished results) (Table $\mathrm{r}$ ). On average, flow of dry matter (DM) on the first day was found to be depressed in these animals and also in more recent experiments with milking cows (unpublished), but the depression was not prolonged and mean flow measured over $3 \mathrm{~d}$ provided a very close estimate of the $5 \mathrm{~d}$ mean. When flow was adjusted for recovery of chromic oxide, administered on paper, the difference in flow between the first day and the $5 \mathrm{~d}$ adjusted mean was eliminated, but although successful in this regard the marker introduced other problems. Adjusted flow was not only more variable than unadjusted, presumably because the marker failed to associate sufficiently closely with the digesta, but it was also higher because recovery of marker was incomplete even after $5-7 \mathrm{~d}$.

Table 1. Comparison of methods of estimating dry matter flow at the proximal duodenum in four dry cows (Sutton et al., 1976) and eight sheep (D. J. Thomson \& D. E. Beever, unpublished).

(Amounts (mean \pm standard errors) are shown relative to the mean daily amounts, unadjusted for recovery of chromic oxide, measured over $5 \mathrm{~d}$ in each collection.)

\begin{tabular}{|c|c|c|c|c|}
\hline \multirow[t]{2}{*}{ 年 } & \multicolumn{2}{|c|}{ Unadjusted } & \multicolumn{2}{|c|}{ Adjustedt } \\
\hline & I st day & $3 \mathrm{~d}$ mean & I st day & $5 \mathrm{~d}$ mean \\
\hline $\begin{array}{l}\text { Dry cows }(8)^{\circ} \\
\text { Sheep }(14)\end{array}$ & $\begin{array}{l}0.92 \pm 0.011 \\
0.94 \pm 0.027\end{array}$ & $\begin{array}{l}1.00 \pm 0.006 \\
0.98 \pm 0.020\end{array}$ & $\begin{array}{l}1 \cdot 04 \pm 0.035 \\
1 \cdot 10 \pm 0.042\end{array}$ & $\begin{array}{l}1 \cdot 06 \pm 0.031 \\
1 \cdot 10 \pm 0.032\end{array}$ \\
\hline
\end{tabular}

- Numbers in parentheses indicate total number of collections

tAdjusted for recovery of chromic oxide.

It is arguable that the failure to obtain complete recovery of the marker after collections lasting up to $7 \mathrm{~d}$ reflects prolonged depression in digesta flow. This explanation seems unlikely and in view of this problem and of the variability in adjusted flow, we prefer to use flow unadjusted for marker recovery unless and until the reliability of a more satisfactory marker is established. The length of such collections is a matter of judgement. The depression on the first day did not occur in all the experiments of Thomson \& Beever, and Oldham \& Ling (1977) found no consistent depression on the first day of $3 \mathrm{~d}$ collections from sheep, but unless convincing evidence to the contrary is obtained, I $\mathrm{d}$ unadjusted flows should be assumed to under-estimate normal flow and a minimum period of $3 \mathrm{~d}$ is advisable.

Use of simple cannulas. The accuracy of flow measurements based on samples from simple cannulas depends entirely on the adequacy of the marker system. It is essential that the marker flows in close association with the component under study. Introduction into the rumen once or twice daily of a marker that flows out 
rapidly can yield entirely erroneous results (Drennan, Holmes \& Garrett, 1970). Evidence that samples are often not representative of total digesta highlights an additional source of error. Not only has wide variation been reported in the relative concentration of liquid and solid phase markers in abomasal samples from sheep (Faichney, 1975), but there is also evidence of bias of up to $20 \%$ towards the solidphase marker in samples from the proximal duodenum (Corse \& Sutton, 1971; MacRae, 1974). A similar bias has been apparent in samples from the proximal duodenum of milking cows, the DM content of samples from simple cannulas being about $15 \%$ greater than from $\mathrm{R} / \mathrm{E}$ cannulas (Sutton \& Oldham, unpublished results). In these instances, use of a single marker to calculate flow of the phase it does not associate with would lead to errors of the order of $15 \%$. This problem can only be overcome by use of dual phase markers as described by Faichney (1975).

Little has been reported concerning the desirable period or frequency of sampling. With frequent feeding, sampling may be restricted to three samples/d for $3 \mathrm{~d}$ (Weston \& Hogan, 1967), but when animals are fed once or twice daily samples must be taken at least every $2 \mathrm{~h}$ over the complete feeding cycle.

Ileal sampling. Fewer studies of the problems of measuring ileal flow have been reported. The principles are the same as those applying to duodenal sampling but the procedure of sampling is made more difficult by the thick, viscous nature of the digesta and the intermittent pattern of flow. As a result, variability in estimates of digesta flow is generally greater at the ileum than at the duodenum.

Feeding frequency. Animals are often fed at intervals of only $\mathrm{I}-3 \mathrm{~h}$ to reduce errors of sampling from simple cannulas and to simplify sampling regimes. This procedure is unacceptable if the feed is normally consumed in one or two meals daily, as is often the case with concentrates, because feeding frequency influences rumen fermentation. Samples must be taken over a complete feeding cycle, but if animals are fed at equal $12 \mathrm{~h}$ intervals and kept under continuous illumination it is probably sufficient to sample during the daytime cycle only.

Technique of choice. Claims that one technique is inherently superior to another are difficult to substantiate. Errors of at least 10-20\% can and often do result from incorrect application of most of the techniques in common use. Choice of a technique remains a matter of personal judgement but, as pointed out by MacRae (1975), each group must accept the responsibility of evaluating the technique it chooses.

It is our opinion that, until the difficulties surrounding the use of markers are fully resolved, the most reliable results are obtained by measurements for at least $3 \mathrm{~d}$ from R/E cannulas. Simple cannulas have many advantages in terms of ease of surgery, maintenance and sampling and a preferable technique would be to sample from simple cannulas on 3 d during a normal digestibility trial, using nonradioactive forms of dual phase markers. However, such a routine should only be adopted when its reliability has been compared with that of long-term total collections from $\mathrm{R} / \mathrm{E}$ cannulas.

Numbers of animals. The coefficient of variation, based on residual variation in Latin Square (LS) designs and sheep $\times$ diet interactions in randomized block 
experiments, has been about $10 \%$ for measurements of DM flow at the duodenum and for faecal DM output in sheep and dry cows at this Institute. On this basis, for detection of a significant $(P<0.05)$ difference with a probability of at least $65 \%$, a $4 \times 4$ LS would be adequate for a $20 \%$ difference but two $6 \times 6$ LS would be needed for a $10 \%$ difference. Detection of a $15 \%$ difference requiring one $6 \times 6 \mathrm{LS}$, would appear to be the practical limit of this type of experiment.

\section{Interpretation}

Digesta consist of three main components: undigested feed, microbial products and endogenous secretions. Difficulties in separating these fractions have limited the extent to which the processes of digestion and microbial synthesis can be satisfactorily interpreted from measures of nutrient flow.

The factors proposed for operation of the ARC scheme (Roy et al., 1977) require the following analyses: total $\mathrm{N}$, nucleic acid- $\mathrm{N}$ and marker (e.g. diaminopimelic acid) in rumen microbes; organic matter (OM), non-ammonia $N$ (NAN) and a microbial marker in duodenal or abomasal contents; and NAN in ileal contents. Of the factors derived from these values, only rumen degradable $N(R D N / F e e d ~ N)$ is a characteristic of individual feeds, varying from 0.4 to 0.8 . All the other factors describing the efficiency of various digestive processes are listed as constants until such time as the extent and causes of any variation can be reliably predicted. It is as much a function of measurements of digesta flow to investigate variables that may affect these 'constant' factors as it is to provide specific values to be identified with individual feeds.

The amount of undegraded feed $\mathrm{N}$ entering the duodenum is defined as total NAN less microbial $\mathbf{N}$ and thus includes NAN of endogenous origin which probably amounts to 0.5 to $2.8 \mathrm{~g} \mathrm{~N} / \mathrm{d}$ in sheep (Harrop, 1974), although few estimates are available. As a result of inclusion of the endogenous component in RDN, true degradability in the rumen of feed proteins is likely to be underestimated by about $0 \cdot$ ro unit.

Various methods have been proposed for identifying microbial $\mathbf{N}$ at the duodenum; none is entirely satisfactory (Buttery \& Cole, 1977), but broad agreement exists about what constitutes 'reasonable' values. For prediction purposes, the amount of microbial synthesis is assumed to bear a constant relationship to energy fermented in the rumen. This is defined in terms of oM apparently digested in the rumen $\left(A D O M_{R u}\right)$ which is preferred to truly digested $O M$ as it is measured directly and does not require identification of microbial and endogenous OM. The accuracy of estimates of microbial $N: A D O M_{R u}$ is particularly vulnerable to errors in measures of digesta flow because any error in the measure of flow is doubled in the ratio.

The measure of amino acid uptake from the small intestines is defined by Roy $e t$ al. (1977) as the apparent digestibility of NAN, adjusted for microbial nucleic acid $\mathrm{N}$, between the proximal duodenum and terminal ileum. It is thus simple to derive, but takes no account of endogenous secretions along the small intestine.

When digesta flow from the stomach is measured beyond the point of entry of 
the bile and pancreatic ducts, derivation of the required factors is more complicated. Assuming a combined secretion rate by these glands of about $500 \mathrm{~g}$ $O M$ and $30 \mathrm{~g} \mathrm{~N}$ daily in a milking cow (van't Klooster \& Rogers, 1969; W. Kaufman \& H. Hagemeister, personal communication) it can be calculated that estimates of $\mathrm{RDN} /$ Feed $\mathrm{N}$ and of $A D O M_{\mathrm{Ru}}$ as a fraction of $O M$ apparently digested throughout the tract (ADOM) are both about 0.1 unit too low, about $15 \%$ of average values, unless adjusted for these secretions. The effect on the estimate of apparent digestibility of NAN in the small intestine is probably small.

\section{Cattle}

The amount of feed consumed and the gross value of the product in the United Kingdom is about five times greater for milking cows than for sheep, yet the number of measurements of digesta flow in sheep far exceeds that in cattle. In literature published outside the USSR, only ten milking cows have been used; only once were more than two of the cows given the same ration, and in only three of the cows was the duodenal cannula anterior to the entry of the bile and pancreatic ducts. Differences in results from cows are large. Estimates of $A D O M_{\mathrm{Ru}}: A D O M$ range from $0.50-0.55$ for rations of concentrates, silage and hay given to two cows with cannulas beyond the point of entry of the bile and pancreatic ducts (Tamminga, 1975) to $0.70-0.75$ for rations of barley, hay and soyabean given to two cows with cannulas immediately after the pylorus (Sutton \& Oldham, unpublished results).

Values obtained with sheep cannot be assumed to apply to milking cows. For instance, sheep and cattle differ in their ability to digest whole cereals (Wilson, Adeeb \& Campling, 1973). Moreover, in most experiments with sheep, diets have been offered at 1 to 2 times maintenance whereas milking cows are normally fed at twice this level. Increases in level of intake reduce methane losses, alter volatile fatty acid proportions in the rumen and decrease ADOM. It is not known to what extent factors required by the proposed scheme are affected, but a reduction in $\mathrm{ADOM}_{\mathrm{Ru}}$ has been reported at higher levels of intake in sheep (Nicholson \& Sutton, 1969). Clearly there is an urgent need to determine values for the required factors in milking cows receiving production rations or to establish whether sheep fed near to maintenance provide an adequate model for growing and lactating cattle.

We are grateful to Dr D. J. Thomson and Dr D. E. Beever for permission to use their unpublished results and to Mrs Rosemary Fulford for statistical advice.

\section{REFERENCES}

Agricultural Research Council (1965). The Nutrient Requirements of Farm Livestock no. 2. Ruminants. London: Agricultural Research Council.

Buttery, P. J. \& Cole, D. J. A. (1977). Proc. Nutr. Soc. 36, 211.

Corse, D. A. (1974). Proc. Nutr. Soc. 33, 14 I.

Corse, D. A. \&utton, J. D. (1971). Proc. Nutr. Soc. 30, 18A.

Drennan, M. J., Holmes, J. H. G. \& Garrett, W. N. (1970). Br. J. Nutr. 24, 961. 
Faichney, G. J. (1975). In Digestion and Metabolism in the Ruminant. p. 277 [I. W. McDonald \& A. C. I. Warner, editors]. The University of New England Publishing Unit.

Harrop, C. J. F. (1974). F. agric. Sci., Camb. 83, 249.

MacRae, J. C. (1974). Proc. Nutr. Soc. 33, 147.

MacRae, J. C. (1975). In Digestion and Metabolism in the Ruminant. p. 26I [I. W. McDonald \& A. C. I. Warner, editors]. The University of New England Publishing Unit.

Moe, P. W. \& Tyrrell, H. F. (1973). Y. Anim. Sci. 37, 183.

Nicholson, J. W. G. \& Sutton, J. D. (1969). Br. F. Nutr. 23, 585.

Oldham, J. D. \& Ling, J. R. (1977). Br. F. Nutr. 37, 333 .

Roy, J. H. B., Balch, C. C., Miller, E. L., Orskov, E. R. \& Smith, R. H. (1977). Proc. 2nd International Symposium on Protein Metabolism and Nutrition, Flevohof. (In the press).

Sutton, J. D. (1976). In Principles of Cattle Production. p. 121 [H. Swan \& W. H. Broster, editors]. London: Butterworths.

Sutton, J. D., Youssef, F. G. \& Oldham, J. D. (1976). Proc. Nutr. Soc. 35, 100A.

Tamminga, S. (1975). Neth. F. agric. Sci. 23, 89.

van't Klooster, A. Th. \& Rogers, P. A. M. (1969). Meded. Landbouwhogeschool Wageningen. $69-11,3$.

Weston, R. H. \& Hogan, J. P. (1967). Aust. F. agric. Res. 18, 789.

Wilson, G. F., Adeeb, N. N. \& Campling, R. C. (1973). F. agric. Sci., Camb. 80, 259. 